\title{
Progesterone withdrawal and RU-486 treatment stimulate apoptosis in specific uterine decidual cells
}

\author{
Bruce C. Moulton ${ }^{1,3}$, Joan Motz ${ }^{1}$, Cleo Serdoncillo ${ }^{1}$, \\ Kamil C. Akcali ${ }^{2}$ and Sohaib A. Khan ${ }^{2}$ \\ 1 Department of Obstetrics and Gynecology, University of Cincinnati College of \\ Medicine, Cincinnati, Ohio 45267-0526 \\ 2 Department of Cell Biology, Neurobiology and Anatomy, University of \\ Cincinnati College of Medicine, Cincinnati, Ohio 45267-0526 \\ 3 corresponding author: Department of Obstetrics and Gynecology, University of \\ Cincinnati, College of Medicine, Cincinnati, Ohio, 45267-0526, USA. \\ tel: 513558 8465; fax: 5135586138 e-mail: Bruce.Moulton@UC.EDU
}

Received 25.01.96; revised 01.06.96; accepted 18.06.96 Edited by C.J. Thiele

\begin{abstract}
Progesterone secretion is required for the growth and differentiation of endometrial stromal cells to form decidual cells. For many cells where a growth factor supports cell growth and proliferation, withdrawal of the growth factor initiates apoptosis. This study determined the time course and tissue location of apoptosis in deciduomal tissue after withdrawal of progesterone or injection of the antiprogestin, RU-486. Total DNA was isolated from decidual tissues at intervals after experimental treatments and separated electrophoretically. Internucleosomal DNA fragmentation characteristic of apoptosis was measured by quantitating levels of the $200 \mathrm{bp}$ fragment. Apoptotic cells in tissue sections were detected by direct immunoperoxidase detection of digoxigenin-labeled DNA. Decidual apoptosis reached maximal levels at $12 \mathrm{~h}$ after withdrawal of progesterone or injection of RU-486. Increased concentrations of apoptotic cells were observed at the periphery of the growing deciduoma and in the antimesometrial deciduoma near the luminal epithelium after both treatments. These results suggest the withdrawal of progestin initiates apoptosis in cells at the early stages of decidualization.
\end{abstract}

Keywords: uterus, endometrium, decidual cells, progesterone, RU-486, apoptosis

Abbreviations: RU-486, antiprogestin; MPA: medroxyprogesterone acetate

\section{Introduction}

During the estrous cycle, blastocyst implantation and stromal decidualization, the apoptosis specific uterine cells complements cell proliferation and enables remodelling of the uterus (Welsh, 1993). Progesterone and estrogen secretion during the estrous cycle control both epithelial proliferation and cell death (Sandow et al, 1979). Decreases in levels of estrogen initiate a wave of cell death (Pollard et al, 1987), (Nawaz et al, 1987). Apoptosis of epithelial cells in ovariectomized mice after estrogen priming was most effectively prevented by progesterone and estrogen treatment (Terada et al, 1989). Early in implantation, luminal epithelial cells in the immediate vicinity of the blastocyst undergo apoptosis initiated by unknown mechanisms (Parr et al, 1987).

Adhesion of the blastocyst results in the decidualization of the endometrial stroma. Decidualization begins in the antimesometrial side of the uterus forming a primary decidual zone, expands to form a secondary zone in the antimesometrium, and eventually transforms stromal cells in the mesometrial region. During pregnancy, both decidual zones regress by apoptosis leaving decidual cells in the mesometrial region to form the decidua basalis (Welsh, 1993; Welsh and Enders, 1985). Decidual regression has been examined in pseudopregnant rats or ovariectomized rats after progestin/estrogen pretreatment (Gu et al, 1994). Nucleosomal DNA fragmentation, a measure of apoptosis, begins in the antimesometrial stroma on day 10 with eventual progression to the mesometrial stroma (Gu et al, 1994). This tissue differentiation in the uterus is accompanied by a differential expression of regulators of apoptosis. The expression of Bax protein, an inducer of apoptosis, is induced: but $\mathrm{Bcl}-2$, an inhibitor of apoptosis, is decreased suggesting that apoptosis plays a major role in decidualization and placenta formation (Akcali et al, 1996).

For many tissues which respond to sex steroids, their regression when these hormones are removed appears to proceed by apoptosis (Thompson, 1994). Antiandrogens or androgen withdrawal induce apoptosis in the glandular epithelium of the prostate with increases in internucleosomal DNA fragmentation in days 1 and 2 post castration (English et al, 1989). Treatment with RU-486 induces apoptosis of the rabbit uterine epithelium and induction of apoptosis by ovariectomy is prevented by progesterone treatment (Rotello et al, 1992). Similar effects of progestin antagonists on epithelial apoptosis in the rat are observed without notable effects on apoptosis in the stroma (Rumpel et al, 1993). After decidualization of the endometrial stroma, however, decidual cells become exquisitely sensitive to progesterone loss (MacDonald et al, 1983; Finn and Pope, 1984). It has also been shown that on days $10-12$ of pseudopregnancy, antimesometrial stromal cells undergo apoptosis despite the presence of progesterone ( $\mathrm{Gu}$ et al, 1994). To address this discrepancy, we examined the hypothesis that decidual regression after progesterone withdrawal proceeds by apoptosis and determined the time course and tissue location of apoptosis in deciduomal tissues after progesterone withdrawal and treatment with RU-486. 


\section{Results}

Ovariectomized rats were given a deciduogenic stimulus after pretreatment with progesterone pellets and estradiol to produce uterine sensitivity. Three days after initiation of decidualization, progesterone pellets were removed and animals killed at intervals afterwards to determine the time course of cell death. By $8 \mathrm{~h}$ after removal of the progesterone pellets, serum progesterone levels decreased to basal levels (Figure 1). DNA was purified from deciduomal tissues collected at intervals after progesterone withdrawal, and electrophoresed on agarose gels. As shown in Figure 2, progesterone withdrawal increased nucleosomal fragmentation in deciduomal DNA. Levels of nucleosomal DNA fragmentation significantly increased to maximal levels by $12 \mathrm{~h}$ after progesterone withdrawal ( $t$ test, $\mathrm{p}<0.01$, Figure 1 ).

Uterine sections from rats at 0 and $12 \mathrm{~h}$ after progesterone withdrawal were stained to determine the tissue location of deciduomal cells sensitive to progesterone withdrawal. Sections were stained with a procedure designed to identify cellular concentrations of $3^{\prime}-\mathrm{OH}$ DNA ends generated by the nucleosomal DNA fragmentation of apoptosis. Concentrations of positively stained deciduomal cells were identified on the periphery of the deciduomal tissue near the myometrium with other isolated positive cells scattered through the tissue. Submyometrial concentrations of positive cells from $12 \mathrm{~h}$ after progesterone withdrawal are shown in Figure $3 \mathrm{~B}$ for comparison with O h in Figure 3A. In Figure 3B, normal decidual cells can be seen on the right, an area of apoptotic cells in the center (arrowhead), and a mixture of normal and apoptotic cells on

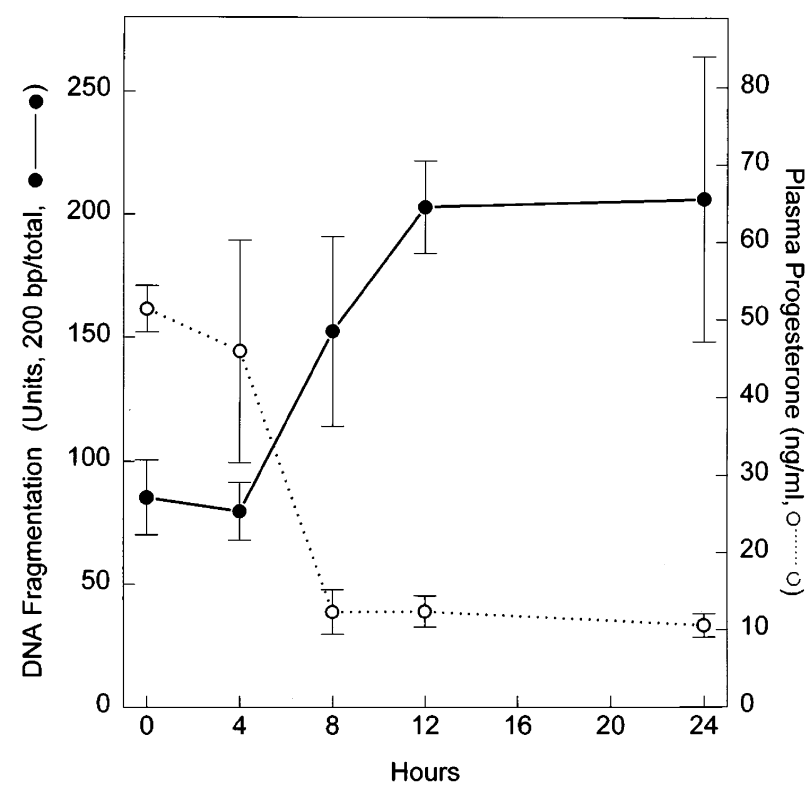

Figure 1 Effect of progesterone withdrawal on DNA fragmentation in decidual tissue. Three days after initiation of decidualization, progesterone pellets were removed and animals were killed at intervals thereafter. Amounts of the $200 \mathrm{bp}$ fragment were determined after electrophoresis of equal amounts of total DNA (-). Serum levels of progesterone were also determined after progesterone withdrawal $(\bigcirc--\bigcirc)$. Each point represents the mean \pm SEM of three rats. the left, adjacent to the myometrium (m). A high power view in Figure $3 \mathrm{C}$ of the submyometrial tissue after progesterone withdrawal shows apoptotic cells (arrowhead) with normal decidual cells nearby.

During early pregnancy, cell death is first observed on Day 7 in decidual cells surrounding the trophoblast in the antimesometrial implantation zone (Welsh and Enders, 1987). (Day 5 is defined as the day of implantation.) As shown in Figure 3D, scattered apoptotic cells were identified in antimesometrial decidual cells and their number and density were increased at $12 \mathrm{~h}$ after progesterone withdrawal (arrowhead, Figure 3E).

The effect of the antiprogestin, RU-486, on apoptosis in decidual cells was determined. Ovariectomized rats were given a deciduogenic stimulus after pretreatment with medroxyprogesterone acetate and estradiol to produce uterine sensitivity. Three days after initiation of decidualization, RU-486 (1.5 mg/0.1 ml sesame oil, sc) was injected and animals killed at intervals afterwards to determine the time course of cell death. RU-486 treatment increased nucleosomal fragmentation in deciduomal DNA. Levels of nucleosomal DNA fragmentation significantly increased by $12 \mathrm{~h}$ ( $t$ test, $\mathrm{p}<0.01$, Figure 4 ). DNA was purified from deciduomal tissues collected at intervals after RU-486 treatment, and electrophoresed on agarose gels. As

\section{Hours after Progesterone Withdrawal}

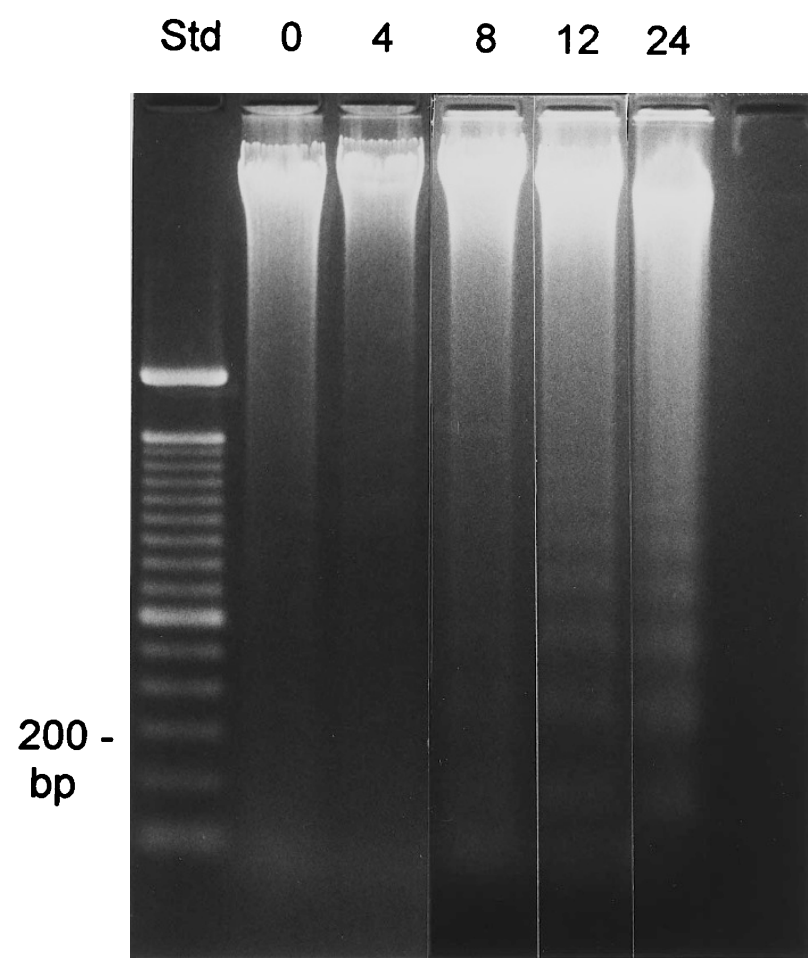

Figure 2 Effect of progesterone withdrawal on DNA fragmentation in decidual tissue. Three days after initiation of decidualization, progesterone pellets were removed and animals were killed at intervals thereafter. Equal amounts of total DNA $(15 \mu \mathrm{g})$ were separated electrophorectically. A $100 \mathrm{bp}$ DNA ladder was used as the size standard (Std). 
shown in Figure 5, RU-486 treatment for $12 \mathrm{~h}$ increased nucleosomal fragmentation in deciduomal DNA.

Uterine sections from rats at 0 and $12 \mathrm{~h}$ after $\mathrm{RU}-486$ treatment were stained to determine the tissue location of deciduomal cells sensitive to antiprogesterone treatment. The distribution of apoptotic cells was similar to the distribution observed after progesterone withdrawal. Concentrations of positively stained deciduomal cells were identified on the periphery of the deciduomal tissue near the myometrium with other isolated positive cells scattered throughout the tissue. Submyometrial concentrations of positive cells from $12 \mathrm{~h}$ after RU-486 are shown in Figure $3 \mathrm{~g}$ for comparison with $\mathrm{Oh}$ in Figure 3F. As in Figure 3B, normal decidual cells can be seen in Figure $3 G$ on the right, an area of apoptotic cells in the center (arrowhead), and a mixture of normal and apoptotic cells on the left, adjacent to the myometrium $(\mathrm{m})$.

\section{Discussion}

Decidualization during early pregnancy results in the growth and terminal differentiation of endometrial stromal cells which have considerable morphologic diversity depending upon their position within the uterus. Decidualization of antimesometrial stromal cells yields epithelioid cells with little extracellular matrix and closely apposed and interdigitated plasma membranes. Mesometrial stromal cells decidualize some $24 \mathrm{~h}$ later yielding smaller, less closely packed decidual
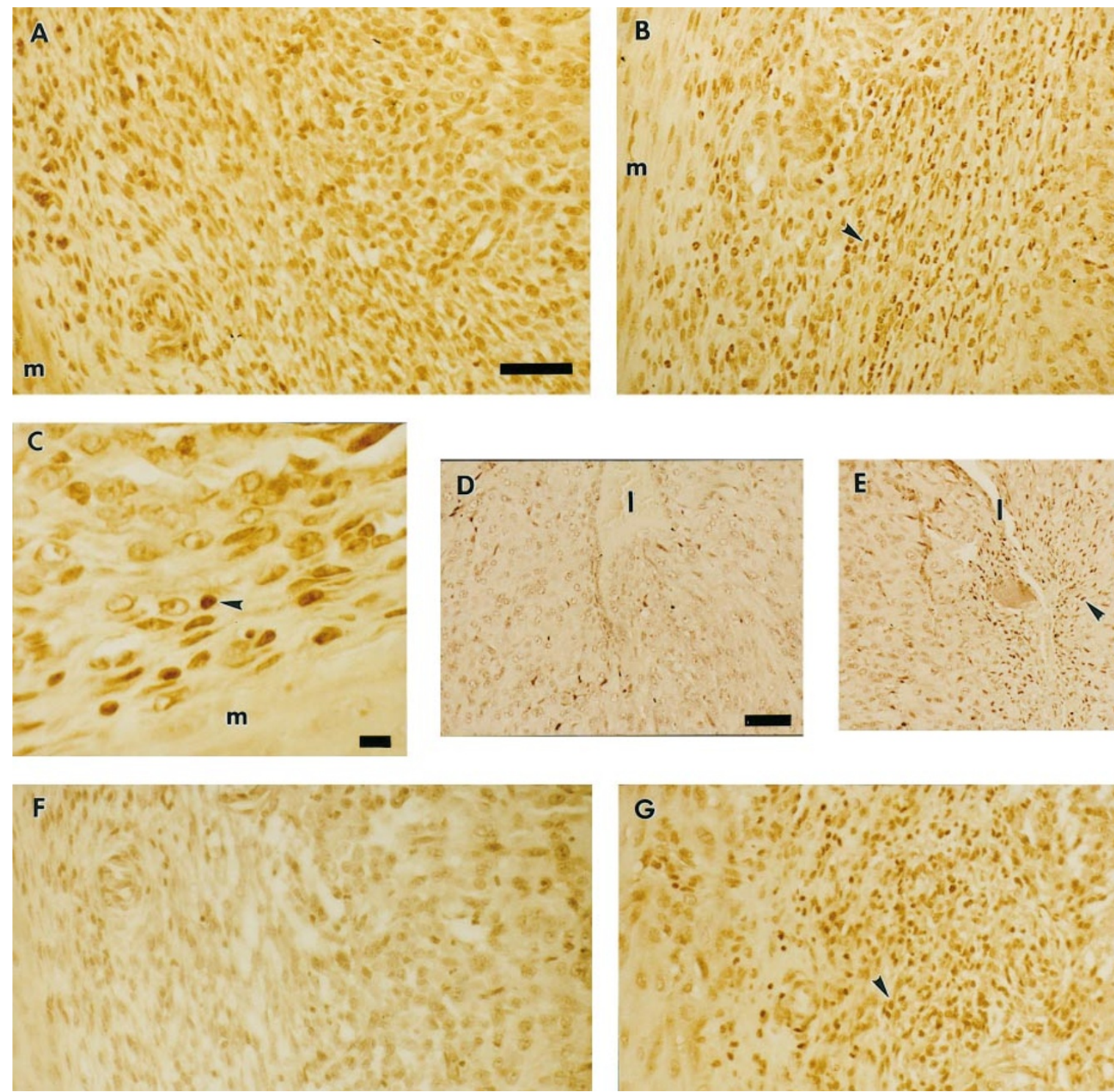

Figure 3 Effect of progesterone withdrawal $(\mathbf{A}-\mathbf{E})$ or RU-486 treatment $(\mathbf{F}-\mathbf{G})$ on apoptosis in endometrial decidual tissue - in situ identification of apoptotic decidual cells. Apoptotic cells were detected by direct immunoperoxidase detection of digoxigenin-labeled DNA in tissue sections. Three days after initiation of decidualization, progesterone pellets were removed or RU-486 $(1.5 \mathrm{mg}, \mathrm{sc})$ was injected and animals were killed at 0 (A, D and $\mathbf{F})$ or $12 \mathrm{~h}(\mathbf{B}, \mathbf{E}$ and $\mathbf{G})$. m=myometrium, I=lumen, arrowheads indicate apoptotic cell nuclei. (A, B and $\mathbf{D}-\mathbf{G}$, original magnification, $80 \times$, black bar=50 $\mu$ mn, C, original magnification, $200 \times$, black bar $=5 \mu \mathrm{m}$. Progesterone withdrawal increased concentrations of apoptotic cells near the myometrium (A vs. B) and in the subepithelial antimesometrial deciduoma (D vs. E). RU-486 treatment increased concentrations of apoptotic cells in decidual cells near the myometrium (F vs. G). 


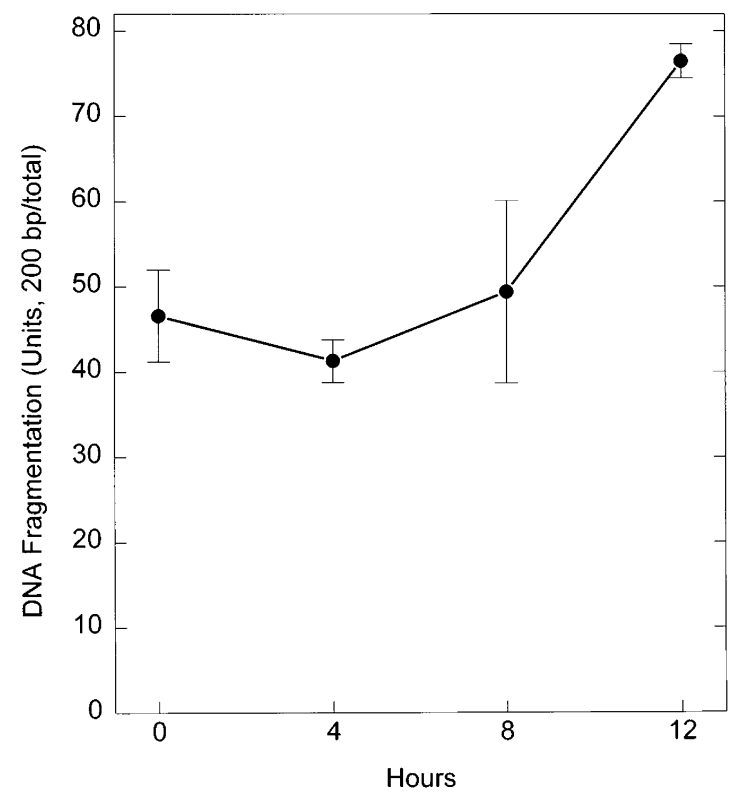

Figure 4 Effect of RU-486 on DNA fragmentation in decidual tissue. Three days after initiation of decidualization, RU-486 (1.5 mg per $\mathrm{ml}, \mathrm{sc}$ ) was injected and animals were killed at intervals thereafter. Amounts of the $200 \mathrm{bp}$ fragment were determined after electrophoresis of equal amounts of total DNA (-) Each point represents the mean \pm SEM of three rats.

cells which have extensive cellular processes that are connected by gap junctions and desmosome-like junctions. Development of the hemochorial placentae in common laboratory rodents requires the controlled cell death of decidual cells which occurs in the same order as their differentiation. Antimesometrial decidual cells in the immediate vicinity of trophoblast cells die within 2 days after the initiation of implantation (Welsh and Enders, 1987). Further degeneration of antimesometrial stromal cells enlarges and remodels the implantation chamber. Extensive degeneration of antimesometrial decidual cells occurs in peripheral regions of the decidua capsularis at about days 11 and 12 (Welsh, 1993).

Because of the similarity in timing and tissue location of decidual cell death during pregnancy and in decidual tissue which develops without the conceptus, cell death appears to be an intrinsic part of endometrial differentiation with the conceptus playing a minor role in its regulation (Welsh, 1993). In both intact pseudopregnant animals and ovariectomized rats treated with progestin and estradiol, nucleosomal DNA fragmentation characteristic of apoptosis is first detected on day 10 in the antimesometrial region with DNA fragmentation observed in the mesometrial region some $24 \mathrm{~h}$ later. Interestingly, neither plasma progesterone levels nor decidual progesterone receptor mRNA levels decreased during decidual regression during days 10-12 of pseudopregnancy which corresponds to days $13-15$ in our study (Gu et al, 1994).

The sensitivity of decidual tissue to progesterone withdrawal is well established. In ovariectomized mice supported with progesterone and estradiol, cellular and

\section{Hours after RU-486 Treatment}

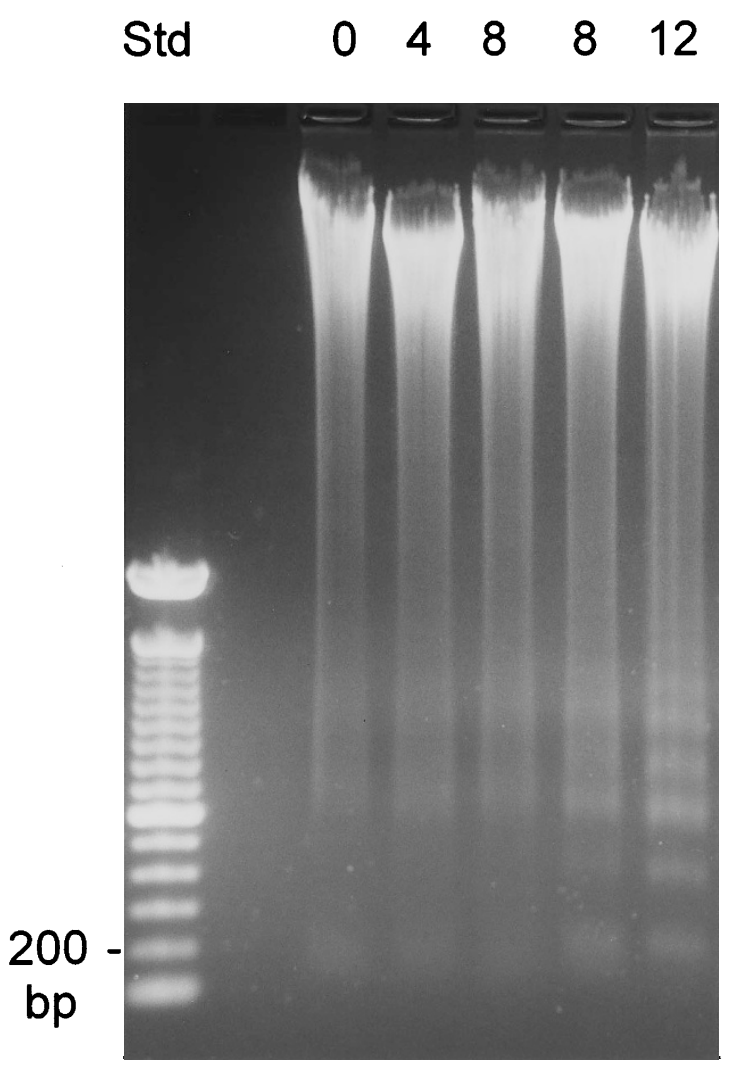

Figure 5 Effect of RU-486 on DNA fragmentation in decidual tissue. Three days after initiation of decidualization, RU-486 $(1.5 \mathrm{mg}, \mathrm{sc})$ was injected and animals were killed at intervals thereafter. Equal amounts of total DNA (15 $\mu \mathrm{g})$ were separated electrophoretically. A 100 bp DNA ladder was used as the size standard (Std).

vascular changes were examined at intervals between 31 and $84 \mathrm{~h}$ after the last progesterone injection (Finn and Pope, 1984). After $45 \mathrm{~h}$, the stroma underwent a series of changes which started with the congestion of dilated blood vessels followed by breakdown of the vessel walls and extravasation of blood. Because decidual cells of the central region showed typical apoptotic changes at the same time, it was not possible in these studies to determine whether death of the decidual cells followed as a result of the blood vessel changes or as a direct effect of a lack of progesterone. Serum levels of progesterone after the last hormone injection were not determined. Our results indicate that progesterone deprivation results in rapid effects on apoptosis in specific decidual cells which appear to precede the blood vessel changes associated with decidual degeneration and detachment.

Either progesterone withdrawal or anti-progestin treatment during the growth phase of decidualization resulted in rapid increases in apoptosis in specific decidual cells at the periphery of the developing deciduoma. It is likely that progesterone withdrawal or anti-progestin treatment initiates apoptosis rather than is associated with apoptotic 
response. Because when progesterone is maintained at the same period, there is no apoptosis. During decidualization it is these cells which incorporate labeled thymidine; once stromal cells have become differentiated they no longer synthesize DNA (Lobel et al, 1967). In several systems, it has been shown that the deregulated progression of cells through the cell cycle results in apoptotic cell death (Meikrantz and Schlegel, 1995). Withdrawal of testosterone causes the apoptotic death of differentiated prostate epithelial cells by driving them from a quiescent $\mathrm{G}_{0}$ state into a cell cycle which they cannot complete (Colombel et al, 1992). For many growth factors which promote passage from $G_{1}$ to $S$ phase of the cell cycle, apoptosis resulting from growth factor withdrawal correlates with arrest in $\mathrm{G}_{1}$ (Meikrantz and Schlegel, 1995). In our studies, apoptosis at the periphery of the deciduoma would appear to result from the loss of a mitogen, progesterone, which coordinates successful cell cycle progession of stromal cells during decidualization. Once stromal cells complete their division and differentiation they are unable to revert to stromal cells, and as decidual cells they become less sensitive to the progesterone withdrawal.

Decidual cells appear to have a finite life span with eventual apoptosis as a feature of their cellular differentiation. Apoptosis in stromal cells around the lumen on day 7 of pregnancy takes place without loss of progesterone (Welsh and Enders, 1987) although apoptosis in this region appeared to be enhanced by progesterone withdrawal in our studies. Antimesometrial cells undergo apoptosis on days $10-12$ of pseudopregnancy despite the maintenance of plasma progesterone levels and decidual cell levels of progesterone receptor mRNA (Gu et al, 1994). Days 10 and 12 of pseudopregnancy correponds to days $13-15$ in our study. Interestingly, we observed the signs of apoptosis upon progesterone withdrawal and RU-486 treatment as early as on day 11 . This suggests that progesterone levels are important to protect cells from apoptosis at the early stages of decidualization, whereas at later stages it loses its control over apoptosis.

Maximal nucleosomal DNA fragmentation at $12 \mathrm{~h}$ after progesterone withdrawal occurs within the same time frame as the effects of progesterone withdrawal on protein synthesis observed in the hamster deciduoma (MacDonald et al, 1983). After the removal of progesterone implants at 3 days after initiation of decidualization, methionine incorporation into acid-precipitable deciduomal proteins decreased by as much as $46 \%$ within $8 \mathrm{~h}$ (MacDonald et al, 1983). When labeled decidual proteins were electrophoresed on IEF-SDS-PAGE 2-D gels, the effects on the synthesis of specific proteins could be identified. As expected, most of the major changes in methionine incorporation into proteins were decreases, but 13 proteins showed increased incorporation with progesterone withdrawal (MacDonald et al, 1983). Initiation of apoptosis induces the synthesis of specific proteins in many systems (Steller, 1995), and apoptosis can be inhibited or delayed by inhibitors of RNA or protein synthesis (Finn and Bredl, 1973). It seems reasonable that several of the 13 proteins showing increased methionine incorporation with progesterone withdrawal could be newly synthesized proteins required for the completion of apoptosis. One group of proteins all related to BCL-2 have either positive or negative regulatory effects of apoptosis (Korsmeyer, 1992; Oltvai and Korsmeyer, 1994). We also have found that increased BAX expression is an early event in stromal cell decidualization (Akcali et al, 1996).

Our studies have shown that progesterone withdrawal or antiprogestin treatment rapidly initiates apoptosis in a limited population of endometrial decidual cells in early part of the decidualization. While these observations indicate that progesterone is necessary to directly support the progession of stromal cells through the cell division and differentiation of decidualization, an indirect effect on the synthesis of growth factors within the decidual tissue cannot be excluded. Apoptosis in specific decidual cells after progesterone withdrawal or with the completion of stromal differentiation presumably requires the enhanced expression of specific apoptosis genes.

\section{Materials and Methods}

\section{Materials}

The following materials were purchased from Gibco-BRL (Gaithersburg, MD): proteinase $\mathrm{K}$, phenol, and $100 \mathrm{bp}$ DNA ladder. Ribonuclease-A and estradiol were purchased from Sigma (St. Louis, MO). GTG agarose was purchased from FMC Bioproducts (Rockland, ME). Medroxyprogesterone acetate (MPA) was generously provided by Upjohn Co. (Kalamazoo, MI).

\section{Animals}

Sprague-Dawley female rats (Zivic-Miller, Zelienpole, PA; 150 -175 g) were maintained on standard rat chow and water ad libitum in animal facilities illuminated between $0500-1900 \mathrm{~h}$. Rats were ovariectomized 2 to 3 weeks before the experiments. In the experiments where we studied the effect of RU-486 on the initiation of apoptosis, rats were pretreated sequentially with estradiol ( $1 \mu \mathrm{g} /$ day; 2 days), no treatment (2 days), MPA ( $3.5 \mathrm{mg}$; single injection $66 \mathrm{~h}$ before intrauterine stimulus) and estradiol (200 $\mathrm{ng}$; single injection $18 \mathrm{~h}$ before intrauterine stimulus) (Moulton, 1994). To study the effect of progesterone withdrawal on the initiation of apoptosis, we implanted progesterone pellets (100 mg/pellet, Innovative Research of America, Toledo, $\mathrm{OH}$ ) subcutaneously instead of injection of MPA. Decidualization was initiated by intrauterine administration of $50 \mu \mathrm{l}$ mineral oil by transcervical injection.

Serum progesterone levels were measured by radioimmunassay (Coat-A-Count, Diagnostic Products Corp., Los Angeles, CA) which had an intraassay coefficient of variation of $3.6-5.8 \%$, an interassay variation of $7.5-10.4 \%$, and an approximate sensitivity of $0.03 \mathrm{ng} / \mathrm{ml}$. Blood was collected at autopsy by heart puncture and allowed to coagulate at room temperature. Serum was collected and stored at $-20^{\circ} \mathrm{C}$.

\section{DNA purification and separation}

DNA was purified by phenol-chloroform-isoamyl alcohol extraction $(24: 24: 1)$ as described previously (Moulton, 1994). DNA samples $(15 \mu \mathrm{g})$ were electrophoretically separated on $1.8 \%$ agarose gels in $0.5 \times$ TPE (45 mM Tris-phosphate and $1 \mathrm{mM}$ EDTA, Ph 8.0) at $70 \mathrm{~V}$ for $2 \mathrm{~h}$ using a $100 \mathrm{bp}$ DNA ladder $(2 \mu \mathrm{g})$ as a mol wt standard. The gel 
was stained with ethidium bromide $(1 \mu \mathrm{g} / \mathrm{ml})$ to visualize the DNA. The gel image was recorded with an IS-500 Digital Imaging System (Alpha Innotech Corp., San Leandro, CA) and the relative amount of the $200 \mathrm{bp}$ fragment determined by image analysis (Image-Pro Plus, Media Cybernetics, Silver Spring, MD).

\section{In situ apoptosis detection}

Cell undergoing apoptosis in paraffin tissue sections were identified using an in situ apoptosis detection kit (ApopTag, Oncor, Gaithersburg, MD) without modification of the manufacturers directions except that an AEC (3-amino-9-ethylcarbazole) staining kit (Sigma, St. Louis, MO) was used for color development. Histological sections were counterstained with hematoxylin and photographed.

\section{Acknowledgements}

We thank Upjohn Co. for medroxyprogesterone acetate and Rousse UCLAF for RU-486. We thank Dr. Laxmi Srivastava for assays of serum progesterone levels. Dr. Sue Heffelfinger and Mr. Jay Card provided helpful advice on histological procedures and interpretation. This work was supported by NIH grant HD29773.

\section{References}

Akcali KC, Khan SA and Moulton BC (1996) Effect of decidualization on the expression of $\mathrm{Bax}$ and $\mathrm{Bcl}-2$ in the rat uterine endometrium. Endocrinology 137: $3123-3130$

Colombel M, Olsson CA, Ng PY and Buttyan R (1992) Hormone-regulated apoptosis results from reentry of differentiated prostate cells onto a defective cell cycle. Cancer Research 52: 4313-4319

English HF, Kypraniou N and Isaacs JT (1989) Relationship between DNA fragmentation and apoptosis in the programmed cell death in the rat prostate following castration. Prostate 15: 233-250

Finn CA and Bredl JCS (1973) Studies on the development of the implantation reaction in the mouse uterus: influence of actinomycin D. Journal of Reproduction and Fertility 34: 247-253

Finn CA and Pope M (1984) Vascular and cellular changes in the decidualized endometrium of the ovariectomized mouse following cessation of hormone treatment: a possible model for menstruation. Journal of Endocrinology 100: $295-300$

Gu Y, Jow GM, Moulton BC, Lee C, Sensibar JA, Park-Sarge OK, Chen TJ and Gibori $G$ (1994) Apoptosis in decidual tissue regression and reorganization. Endocrinology 135: 1272-1279
Korsmeyer SH (1992) Bcl-2 initiates a new category of oncogenes: regulators of cell death. Blood 80: 879-886

Lobel BL, Levy E and Shelesnyak MC (1967) Studies on the mechanism of nidation XXXIV Dynamics of cellular interactions during progesterone and implantation in the rat. Acta Endocrinology (Supplement) 123: 7-109

MacDonald RG, Morency KO and Leavitt WW (1983) Progesterone modulation of specific protein synthesis in the decidualized hamster uterus. Biology of Reproduction 28: 753-766

Meikrantz W and Schlegel R (1995) Apoptosis and the cell cycle. Journal of Cellular Biochemistry 58: 160-174

Moulton BC (1994) Transforming growth factor- $\beta$ stimulates endometrial stromal apoptosis in vitro. Endocrinology 134: 1055-1060

Nawaz S, Lynch MP, Galand P and Gerschenson LE (1987) Hormonal regulation of cell death in rabbit uterine epithelium. Americal Journal of Pathology 127:51-59

Oltvai ZN and Korsmeyer SJ (1994) Checkpoints of dueling dimers foil death wishes. Cell 79: $189-192$

Parr EL, Tung HN and Parr MB (1987) Apoptosis as the mode of uterine epithelial cell death during embryo implantation in mice and rats. Biology of Reproduction 36 : 211-225

Pollard JW, Pacey J, Cheng SVY and Jordan EG (1987) Estrogens and cell death in murine uterine luminal epithelium. Cell and Tissue Research 249: 533-540

Rotello RJ, Lieberman RC, Lepoff RB and Gerschenson LE (1992) Characterization of uterine epithelium apoptotic cell death kinetics and regulation by progesterone and RU 486. Am. J. Pathol. 140: 449-456

Rumpel E, Michna H and Kuhnel W (1993) Morphology of the rat uterus after longterm treatment with progesterone antagonists. Annals of Anatomy 175: 141149

Sandow BA, West NB, Normal RL and Brenner RM (1979) Hormonal control of apoptosis in hamster uterine luminal epithelium. American Journal of Anatomy 156: $15-36$

StellerH (1995) Mechanisms and genes of cellular suicide. Science 267: 1445-1449

Terada N, Yamamoto R, Takada T, Miyake T, Terakawa N, Wakimoto H, Taniguchi H, Li W, Kitamura Y and Matsuomoto K (1989) Inhibitory effect of progesterone on cell death of mouse uterine epithelium. Journal of Steroid Biochemistry 33: $1091-1096$

Thompson EB (1994) Apoptosis and steroid hormones. Molecular Endocrinology 8 : $665-673$

Welsh AO (1993) Uterine cell death during implantation and early placentation. Microsc. Res. Tech. 25: 223-245

Welsh AO and Enders AC (1985) Light and electron microscopic examination of the mature decidual cells of the rat with emphasis on the antimesometrial decidua and its degeneration. American Journal of Anatomy 172: 1-29

Welsh AO and Enders AC (1987) Trophoblast-decidual cell interactions and establishment of maternal blood circulation in the parietal yolk sac placenta of the rat. Anatomical Record 217: 203-219 